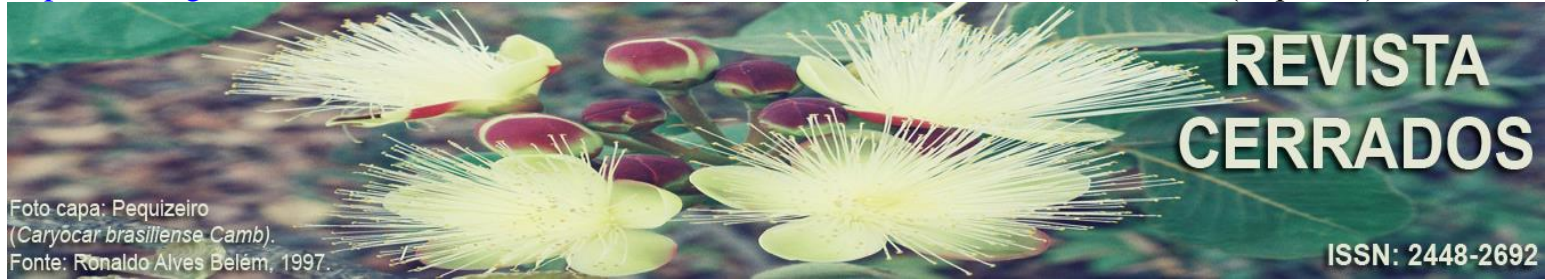

\title{
ESTIMATIVA DE PASSIVOS NA BACIA HIDROGRÁFICA DO CÓRREGO CAIDOR, SILVÂNIA - GOIÁS, COMO SUBSÍDIO À CRIAÇÃO DE UMA ÁREA DE PROTEÇÃO AMBIENTAL
}

\section{ESTIMATE OF LIABILITIES AT THE CAIDOR WATERSHED, SILVÂNIA - GOIÁS, AS A SUBSIDY FOR THE CREATION OF AN ENVIRONMENTAL PROTECTION AREA}

\section{ESTIMACIÓN DE PASIVOS EN LA CUENCA HIDROGRÁFICA DEL ARROYO CAIDOR, SILVANIA - GOIÁS, COMO SUBSIDIO PARA LA CREACIÓN DE UN ÁREA DE PROTECCIÓN AMBIENTAL}

\author{
Jaila Raiane Barbosa de Souza \\ Universidade Federal de Goiás - UFG, Goiânia, Goiás, Brasil \\ E-mail: <jaila.raiane@hotmail.com>. \\ Andrelisa Santos de Jesus \\ Universidade Federal de Goiás - UFG, Goiânia, Goiás, Brasil \\ E-mail: <andrelisajesus@ufg.br>. \\ Manuel Eduardo Ferreira (iD) 9 \\ Universidade Federal de Goiás - UFG, Goiânia, Goiás, Brasil \\ E-mail: <manuel@ufg.br>.
}

\section{RESUMO}

Áreas de Proteção Ambiental são normalmente associadas às Unidades de Conservação, atuando como uma zona de proteção da biodiversidade, especialmente na região de borda, mais afetada por desmatamentos e queimadas. Porém, sua adoção se dá também como proteção às regiões hidrográficas, como aquelas com presença de nascentes e pontos de captação para abastecimento público. Este é o caso da bacia hidrográfica do córrego Caidor, no município de Silvânia, Goiás. Neste contexto, esse estudo busca subsidiar a implantação de uma APA na bacia do córrego Caidor, por meio de análise temporal sobre o uso da terra na região. Para tanto, foi organizado um extenso banco de dados, composto por imagens de satélites (Sentinel), localização de agroindústrias, poços e barragens, pivôs de irrigação, além do atual uso e cobertura da terra (em conjunto com dados do Cadastro Ambiental Rural CAR). Como resultado deste levantamento, são apresentados os mapas com os passivos ambientais na área de estudo, visando a determinação da APA e controle das propriedades 
SOUZA, J. R. B.; SANTOS DE JESUS, A.; FERREIRA, M. E.

Estimativa de passivos na bacia hidrográfica do Córrego Caidor, Silvânia - Goiás, como subsídio à criação de uma área de proteção ambiental

rurais, especialmente daquelas com maior potencial poluidor. Cerca de $80 \%$ desta bacia apresenta uso da terra para fins agropecuários, com seus respectivos passivos ambientais associados à pressão sobre os recursos hídricos.

Palavras-chave: Monitoramento Ambiental. Área de Preservação Permanente. Sentinel.

\begin{abstract}
Environmental Protection Areas (APA) are typically associated with Conservation Units, acting as a biodiversity protection zone, especially in the border region, most affected by deforestation and burnings. However, its adoption also occurs as protection for hydrographic areas, such as those with springs and points of capture for public supply. It is the case of the hydrographic basin of the Caidor river, in the municipality of Silvânia, Goiás (Brazil). In this context, this study seeks to subsidize an APA's implementation in the Caidor river basin through temporal analysis on land use in the region. To this end, an extensive database was organized, consisting of satellite images (Sentinel platform), location of agro-industries, wells and dams, irrigation pivots, and the current land use and land cover maps (together with data from the Rural Environmental Registry - CAR). As a result of this survey, the maps with the environmental liabilities in the study area are presented, aiming to determine the APA and control of the rural properties, especially those with more significant polluting potential. About $80 \%$ of this basin has land use for agricultural purposes, with their respective environmental liabilities associated with water resources pressure.
\end{abstract}

Keywords: Environmental Monitoring. Permanent Preservation Area. Sentinel.

\title{
RESUMEN
}

Las Áreas de Protección Ambiental están normalmente asociadas a Unidades de Conservación, actuando como una zona de protección de la biodiversidad, más afectada por la deforestación y los incendios. Sin embargo, su adopción también se da como protección para regiones hidrográficas, como aquellas con presencia de manantiales y puntos de captación para abastecimiento público. Este es el caso de la cuenca hidrográfica del arroyo Caidor, en el municipio de Silvânia, Goiás (Brasil). Este estudio busca subsidiar la implementación de un APA en la cuenca del arroyo Caidor, a través del análisis temporal del uso del suelo en la región. Para ello, se organizó una extensa base de datos que consta de imágenes satelitales (Sentinel), ubicación de agroindustrias, pozos y presas, pivotes de riego, además del uso actual y cobertura del suelo (junto con datos del Registro Ambiental Rural - CAR). Como resultado, se presentan los mapas con los pasivos ambientales en el área de estudio, para determinación del APA y control de las propiedades rurales, especialmente aquellas con mayor potencial contaminante. Alrededor del $80 \%$ de esta cuenca tiene uso de suelo para fines agrícolas, con sus respectivos pasivos ambientales asociados a la presión sobre los recursos hídricos.

Palabras-clave: Monitoreo Ambiental. Área de Preservación Permanente. Sentinel. 
SOUZA, J. R. B.; SANTOS DE JESUS, A.; FERREIRA, M. E.

Estimativa de passivos na bacia hidrográfica do Córrego Caidor, Silvânia - Goiás, como subsídio à criação de uma área de proteção ambiental

\section{INTRODUÇ̃̃̃O}

O município de Silvânia possui uma grande vocação para atividades agropecuárias, com uma contribuição importante em seu Produto Interno Bruto (IBGE, 2020). Em contraponto às atividades de agricultura e pecuária responsáveis pela supressão da vegetação nativa do cerrado, o município conta com existência de uma Floresta Nacional (FLONA). Essa unidade de conservação tem despertado o interesse da administração pública municipal quanto às questões ambientais, bem como atraído a presença de pesquisadores para a área. Por este motivo, uma pesquisa ecológica de longa duração (PELD) tem sido desenvolvida em Silvânia, com o intuito de investigar a conectividade funcional e antropização da paisagem, especialmente na FLONA e seu entorno imediato.

O presente estudo faz parte do escopo desse projeto PELD, e visa atender uma demanda da gestão municipal quanto ao gerenciamento ambiental da bacia do córrego Caidor. Nesta bacia está localizado o manancial de captação de águas para o abastecimento da cidade de Silvânia. Existe por parte do município a intenção de implantação de uma APA na bacia, atrelada a um programa de pagamento por serviços ambientais.

O fato é que a bacia deste córrego se encontra altamente antropizada. No final da estação seca de 2017, o córrego Caidor entrou numa condição de esgotamento hídrico, causando, como esperado, sérios problemas de abastecimento de água na área urbana, com a necessidade urgente de se instalar um novo ponto de captação de água.

Diante desse contexto, o estudo ora apresentado objetivou cartografar e analisar o uso e a cobertura da terra, indicar os passivos ambientais oriundos das atividades agropecuárias desenvolvidas na bacia do córrego Caidor e subsidiar, com informações técnicas e científicas, a implantação de um programa de pagamento por serviços ambientais e a criação de uma APA de uso sustentável na referida bacia. 
SOUZA, J. R. B.; SANTOS DE JESUS, A.; FERREIRA, M. E.

Estimativa de passivos na bacia hidrográfica do Córrego Caidor, Silvânia - Goiás, como subsídio à criação de uma área de proteção ambiental

\section{MATERIAIS E MÉTODOS}

\section{Área de estudo}

Silvânia é um município do estado de Goiás, com extensão de 2.345,9 km² e população estimada de 20.478 habitantes (IBGE, 2017), localizado na denominada "Região da Estrada de Ferro", na mesorregião do Sul Goiano, microrregião de Pires do Rio (Figura 1). Historicamente, sua criação esteve ligada com a mineração de ouro na região, em 1857 , atraindo a chegada de imigrantes de várias partes do país. Hoje, sua economia está firmada na agropecuária, principalmente nas culturas de soja, milho e pasto cultivado.

A bacia hidrográfica do córrego Caidor está localizada na porção sul do município e ao sul da malha urbana. Este tem suas cabeceiras posicionadas ao norte e entalha-se em direção ao sul, onde bifurca-se o córrego Variado, o qual, em cerca de 5 quilômetros ao sul, tem seu exultório desaguando no rio dos Bois (Figura 1). Ao norte, a bacia do córrego Caidor limita-se com seu divisor de águas, a bacia do ribeirão Vermelho, onde estão a FLONA e área urbana de Silvânia.

Considerando que essa pesquisa visou subsidiar a aprovação de uma lei para pagamento por serviços ambientais e a implantação de uma APA, a legislação ambiental vigente foi levada em consideração para delimitação desta área de amortecimento. Segundo a lei 9.985/2000, que instituiu o Sistema Nacional de Unidades de Conservação da Natureza (SNUC), zonas de amortecimento são necessárias para a manutenção adequada das unidades de conservação. Tais áreas, localizadas no entorno de unidades de conservação, preveem que as atividades humanas estejam sujeitas a normas e restrições específicas, com o propósito de minimizar os impactos negativos sobre a unidade.

A resolução Conama 13/1990 estabelece que, para unidades de conservação sem plano de manejo, a zona de amortecimento seja sempre de $10 \mathrm{~km}$. Assim, a faixa de influência utilizada nesse estudo teve como recorte espacial a bacia hidrográfica do córrego Caidor, com 41,6 $\mathrm{Km}^{2}$, e sua respectiva área de amortecimento, com $822,5 \mathrm{Km}^{2}$. 
SOUZA, J. R. B.; SANTOS DE JESUS, A.; FERREIRA, M. E.

Estimativa de passivos na bacia hidrográfica do Córrego Caidor, Silvânia - Goiás, como subsídio à criação de uma área de proteção ambiental

Figura 1: Localização da área de estudo, ressaltando os limites da bacia do Caidor e da FLONA

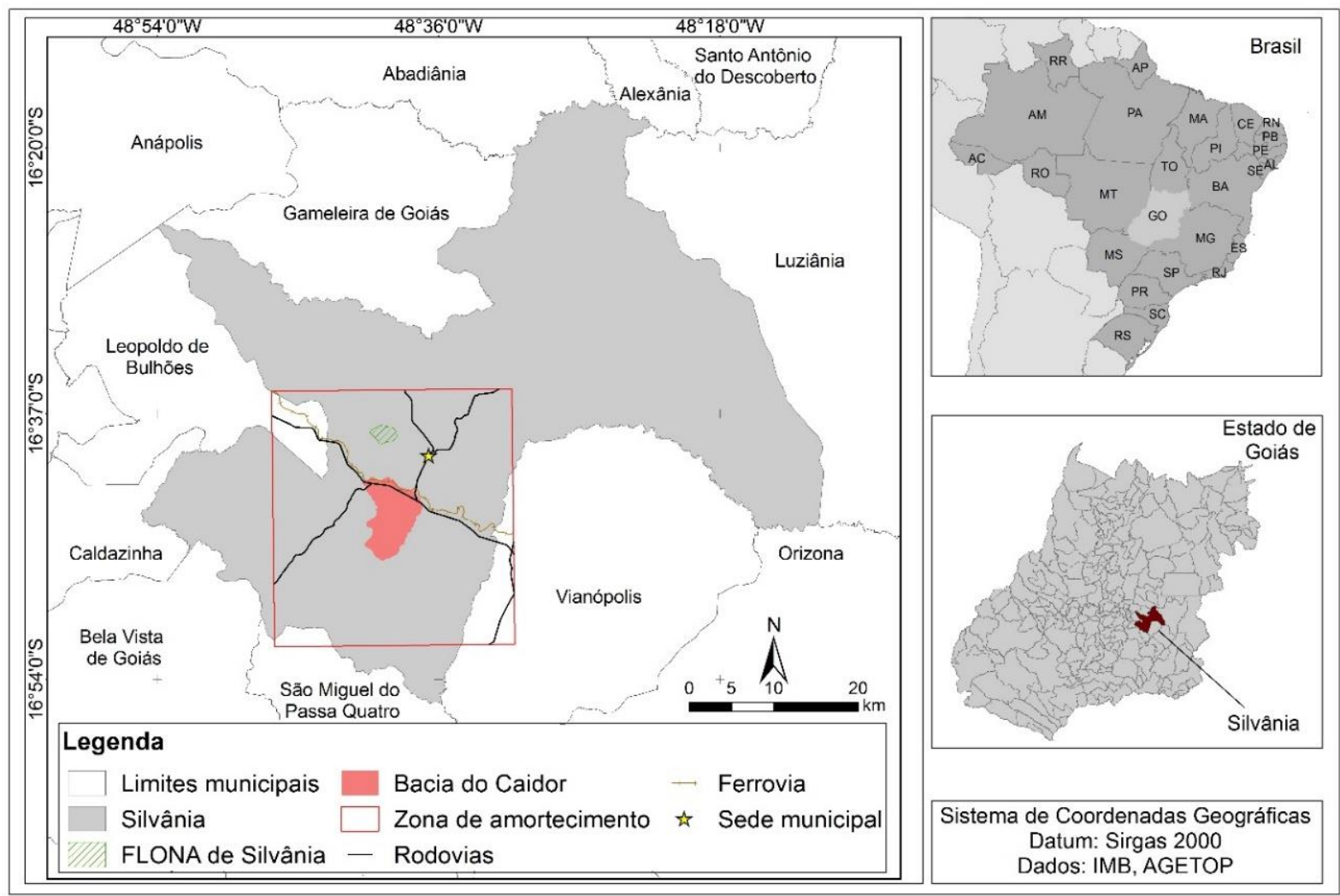

Fonte: IMB (2017), AGETOP (2012).

\section{Procedimentos Metodológicos}

Esta pesquisa foi realizada em três etapas, sendo elas: elaboração de um banco de dados cartográfico referente à área de estudo; visitas de campo para reconhecimento da bacia e validação dos mapeamentos preliminares; e, por fim, tratamento e análise dos mapas.

\section{Banco de Dados Cartográfico}

Um banco de dados cartográfico foi organizado para a pesquisa, utilizando-se a rede de drenagem delimitada manualmente sobre imagens disponíveis na plataforma Google Earth, com escala fixada em 1:10.000. Somou-se a esse banco de dados uma cena do satélite Sentinel 2A, referente ao dia 31 de agosto de 2017, com 10 metros de resolução espacial. Com as informações espaciais obtidas no Google Earth (drenagem) e da imagem do Sentinel, 
SOUZA, J. R. B.; SANTOS DE JESUS, A.; FERREIRA, M. E.

Estimativa de passivos na bacia hidrográfica do Córrego Caidor, Silvânia - Goiás, como subsídio à criação de uma área de proteção ambiental

foi feita a delimitação manual da bacia, com posterior geração do buffer (ou limite) referente à zona de amortecimento.

\section{Mapeamento do Uso e Cobertura da Terra}

Com a bacia e área de amortecimento delimitados, a imagem de satélite da plataforma Sentinel $2 \mathrm{~A}$ foi inspecionada visualmente (também com escala fixada em 1:10.000), empregando-se um Sistema de Informação Geográfica (SIG), para fins de identificação e cartografia das classes de uso e cobertura da terra. Utilizou-se a legenda conforme a proposta do Manual Técnico de Uso da Terra (IBGE, 2013), obtendo-se as seguintes classes:

- Pastagem - Área para o pastoreio de gado, área sem a presença de gado, mas com a presença de gramíneas e áreas degradadas com vegetação rasteiras pastejáveis.

- Agricultura - Área para plantação, normalmente caracterizada por grandes áreas com formas geométricas, com homogeneidade e características típicas para o mês de agosto (período seco, entressafra).

- Silvicultura - Área caracterizada pelo plantio de eucalipto.

- Vegetação Nativa - Área caracterizada pela presença de vegetação nativa, especialmente nas margens dos cursos hídricos da área de estudo.

- Área Urbana - Área correspondente ao limite das cidades.

- Indústrias - Área com a presença de indústrias, silos e grandes galpões, e as áreas de influência dos mesmos (como estacionamento, pátio, solo exposto e limite de cerca ao redor da área).

- Barragens/Tanques/Represas - Área de lâminas d’água de represas, barragens e tanques.

- Propriedades Rurais - Áreas caracterizadas pelas edificações nas sedes das propriedades rurais.

- Extração - Área de solo exposto, com características de retirada de material mineral. 
SOUZA, J. R. B.; SANTOS DE JESUS, A.; FERREIRA, M. E.

Estimativa de passivos na bacia hidrográfica do Córrego Caidor, Silvânia - Goiás, como subsídio à criação de uma área de proteção ambiental

Além das classes mencionadas, também foram organizados os mapas de pivôs de irrigação, tanques e barragens. Os pontos de indústrias foram identificados nas proximidades das áreas centrais/industriais, onde silos e grandes galpões são representados por grandes estruturas nas imagens de satélite. Os pontos de barragens foram identificados nas imagens por formas geométricas, em sua maioria triangulares, com significativa superfície de lâmina d'água. Os tanques, por sua vez, foram identificados como formas geométricas quadradas, aglomeradas ou isoladas, em sua maioria relacionada com a piscicultura, com superfícies de lâminas d'água menores, se comparado com as barragens. Os pivôs de irrigação, por sua vez, foram adquiridos na plataforma online do Sistema Estadual de Geoinformação do Estado de Goiás - SIEG/Instituto Mauro Borges ${ }^{1}$, em formato vetorial (shapefile), referentes ao ano de 2015. Estes pivôs foram atualizados por inspeção visual, com base na imagem de satélite Sentinel, referente ao ano de 2017.

Também foram verificados os passivos ambientais em APPs, levando-se em consideração a cobertura de dossel. Para se determinar o percentual de integralidade do dossel (mata de galeria), foram realizados buffers de 30, 50 e 100 metros ao redor do córrego Caidor. Esses buffers foram sobrepostos às classes de uso e cobertura da terra, facilitando o reconhecimento das áreas sem vegetação nativa, já convertidas para outros usos e coberturas.

\section{Tamanho e quantidade de propriedades rurais}

Os dados de propriedades rurais empregados nesse estudo foram adquiridos do Cadastro Ambiental Rural (CAR) e da base de dados do Instituto de Manejo e Certificação Florestal e Agrícola (IMAFLORA). A base do $\mathrm{CAR}^{2}$ mostrou-se com algumas lacunas na lista de propriedades referentes à bacia, enquanto a do IMAFLORA ${ }^{3}$ apresentou informações para toda a área estudada, embora num arranjo para propriedades maiores. A base disponibilizada pelo IMAFLORA é derivada da malha fundiária do Brasil (IMAFLORA, GeoLab/USP e Royal Institute of Technology), disponibilizando imóveis privados registrados pelo INCRA e pelo CAR, bem como assentamentos rurais e quilombolas, na escala de 1:250.000, referente ao ano de 2017, para o bioma Cerrado.

\footnotetext{
${ }^{1}$ http://www.sieg.go.gov.br/

2 http://www.car.gov.br

3 https://www.imaflora.org
} 
SOUZA, J. R. B.; SANTOS DE JESUS, A.; FERREIRA, M. E.

Estimativa de passivos na bacia hidrográfica do Córrego Caidor, Silvânia - Goiás, como subsídio à criação de uma área de proteção ambiental

Figura 2: Mapas de tamanho das propriedades rurais: a) Tamanho das propriedades segundo o CAR; b) Tamanho das propriedades segundo o IMAFLORA

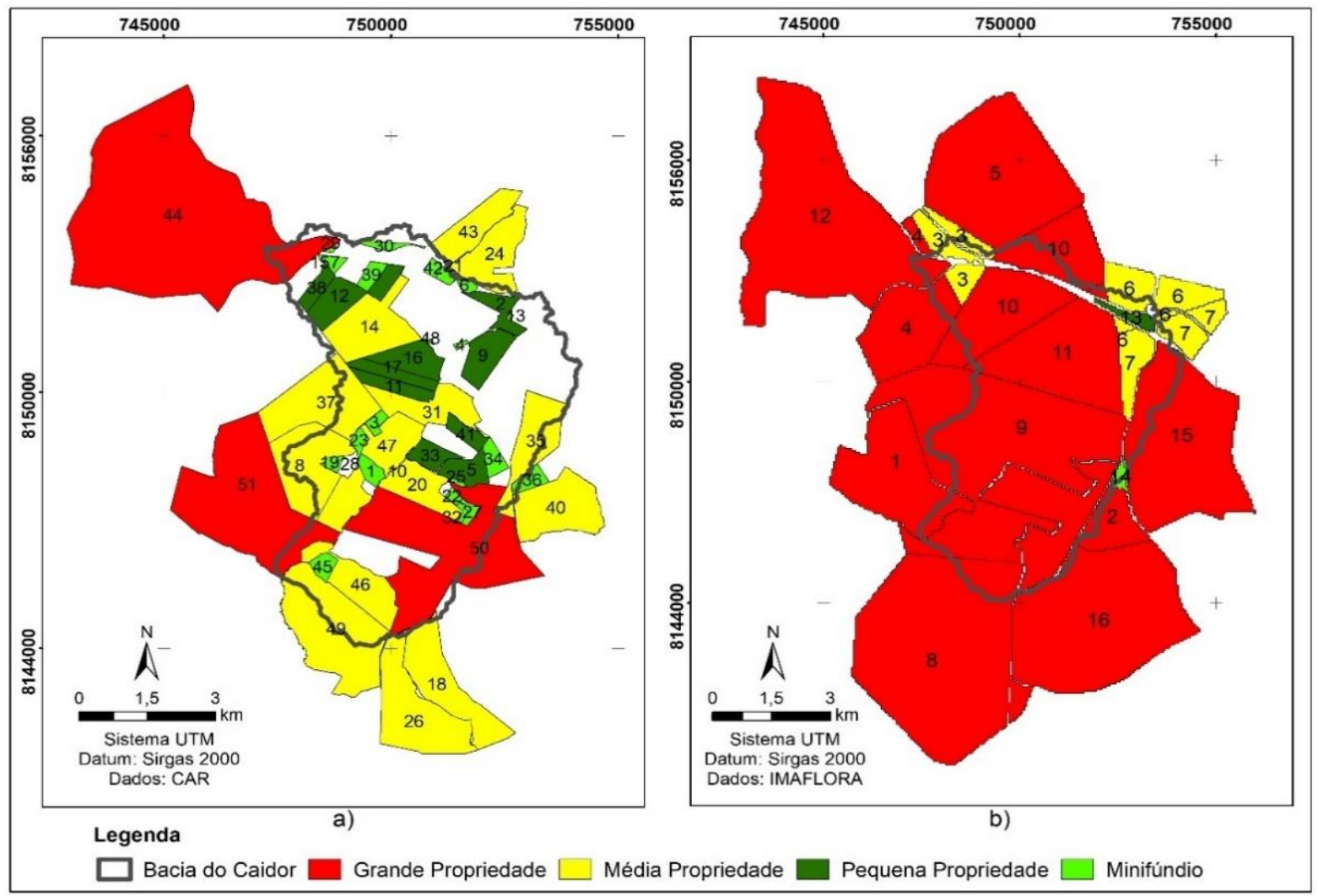

Fonte: CAR (2017), IMAFLORA (2017).

De acordo com os dados do CAR, existem 51 propriedades inseridas na bacia do córrego Caidor, sendo majoritariamente de médias propriedades, entre 4 e 15 módulos fiscais (Figura 2a). Segundo o IMAFLORA, existem 16 propriedades inseridas na bacia do córrego Caidor, sendo majoritariamente de grandes propriedades, com mais de 15 módulos fiscais (Figura 2b). Essa diferença no número de propriedades, entre as duas bases apresentadas, se deve ao fato de a base de dados do CAR ser alimentada por autodeclaração, enquanto a base de dados do IMAFLORA é alimentada por dados georreferenciados do INCRA. Destaca-se que um módulo fiscal em Silvânia é equivalente a 30 hectares.

\section{Visitas de Campo}

Para validação do mapa de uso e cobertura da terra, foram feitas 3 visitas de campo à área de estudo, nos dias 31 de agosto, 19 de outubro e 16 de novembro de 2017. 
SOUZA, J. R. B.; SANTOS DE JESUS, A.; FERREIRA, M. E.

Estimativa de passivos na bacia hidrográfica do Córrego Caidor, Silvânia - Goiás, como subsídio à criação de uma área de proteção ambiental

Nessas visitas, realizaram-se registros fotográficos e coletas de pontos de GPS em áreas representativas das classes mapeadas. Durante as visitas, constatou-se a predominância de atividades agropecuárias e a presença de indústrias, barragens, tanques para criação de peixes (próximos ao canal fluvial), além de mineração referente à extração de cascalho laterítico próximas aos divisores de água (topos).

\section{Passivo Ambiental}

Segundo o IBAMA, "passivo ambiental é o termo utilizado para denominar potenciais riscos de caráter ambiental, relacionados ao cumprimento da legislação ambiental vigente na data da avaliação ou a quaisquer obrigações de fazer, de deixar de fazer, de indenizar, de compensar ou de assumir qualquer outro compromisso de caráter ambiental" (IBAMA, 2002). Nesse sentido, Peccini (2012) destaca que passivo ambiental é constituído por obrigações adquiridas envolvendo entidades, pessoas, propriedades e outros com o meio ambiente, sendo que estas são oriundas de alguma atividade que cause dano ambiental.

Os dados de passivo ambiental desse estudo foram gerados levando-se em conta o limite das propriedades rurais, vinculado sempre a um responsável. Como forma de manter o anonimato dos proprietários, foi utilizada uma numeração criada para este estudo, a fim de facilitar a análise. Para a análise do passivo, foi considerado o mapeamento de uso e cobertura da terra e o quantitativo de indústrias, extração mineral, tanques e barragens levantados na pesquisa, dos quais foi possível extrair as estatísticas em cada propriedade, tanto para os dados de propriedades do CAR, quanto para os do IMAFLORA, conforme ilustrado nas Figuras $2 \mathrm{a}$ e $2 \mathrm{~b}$.

Assim, buscou-se identificar os usos que podem resultar em danos ambientais, se não estiverem funcionando de maneira correta. O levantamento realizado visou identificar todos os tipos de usos, como subsídio para a proposta de criação da Área de Proteção Ambiental (APA) na bacia do Caidor. 
SOUZA, J. R. B.; SANTOS DE JESUS, A.; FERREIRA, M. E.

Estimativa de passivos na bacia hidrográfica do Córrego Caidor, Silvânia - Goiás, como subsídio à criação de uma área de proteção ambiental

\section{RESULTADOS E DISCUSSÕES}

\section{Uso e Cobertura da Terra}

Os mapas nas Figuras 3 e 4, bem como as informações das Tabelas 1 e 2, ilustram, respectivamente, o uso e cobertura da terra para a bacia do córrego Caidor e sua zona de amortecimento para a área de proteção ambiental (APA) em processo de criação.

Tabela 1 - Porcentagem de uso e cobertura da terra na bacia do córrego Caidor $\left(\mathrm{em} \mathrm{km}^{2} \mathrm{e}\right.$ hectare)

\begin{tabular}{lrrr}
\hline \multicolumn{1}{c}{ Uso e cobertura da terra } & \multicolumn{1}{c}{ Área $\mathbf{~ K m}^{\mathbf{2}}$} & \multicolumn{1}{c}{ Área Ha } & \multicolumn{1}{c}{$\%$} \\
Agricultura & 25,2 & $2.522,7$ & 60,6 \\
\hline Pastagem & 7,5 & 751,3 & 18 \\
Vegetação Nativa & 6,4 & 641,8 & 15,4 \\
\hline Silvicultura & 1,4 & 139 & 3,3 \\
Propriedades Rurais & 0,7 & 72,2 & 1,7 \\
Indústrias & 0,2 & 23 & 0,6 \\
Extração & 0,1 & 9,6 & 0,2 \\
Barragens/Represas/ & 0,04 & 4,2 & 0,1 \\
Tanques & & & \\
Total & $\mathbf{4 1 , 6}$ & $\mathbf{4 . 1 6 3 , 7}$ & $\mathbf{1 0 0}$ \\
\hline
\end{tabular}

Fonte: Dados obtidos pelos autores a partir do tratamento de imagens Sentinel / 2017.

Tabela 2 - Porcentagem de uso e cobertura da terra na zona de amortecimento (ZA) da bacia do córrego Caidor (em $\mathrm{km}^{2}$ e hectare)

\begin{tabular}{l|r|r|r}
\hline \multicolumn{1}{c|}{ Uso e cobertura da terra } & Área $\mathbf{K m}^{2}$ & \multicolumn{1}{|c|}{$\begin{array}{c}\text { Área } \\
\text { Ha }\end{array}$} & \multicolumn{1}{c}{$\%$} \\
\hline Agricultura & 413,3 & 41.334 & 50,3 \\
Vegetação Nativa & 198 & 19.802 & 24,1 \\
\hline Pastagem & 189 & 18900,8 & 23 \\
Silvicultura & 9,4 & 943,5 & 1,2 \\
\hline Área Urbana & 7,4 & 735,9 & 0,9 \\
Propriedades Rurais & 2,8 & 278,3 & 0,3 \\
\hline Barragens/Represas/ & 1,7 & 171,6 & 0,2 \\
Tanques & & & \\
Indústrias & 0,5 & 54,4 & 0,1 \\
\hline Extração & 0,3 & 28,6 & 0,03 \\
Total & $\mathbf{8 2 2 , 5}$ & $\mathbf{8 2 . 2 4 9}$ & $\mathbf{1 0 0}$ \\
\hline
\end{tabular}

Fonte: Dados obtidos pelos autores a partir do tratamento de imagens Sentinel / 2017.

As informações de uso e cobertura da terra dentro dos limites da bacia do córrego Caidor indicam uma forte utilização pela agricultura, correspondente a $61 \%$ da área da bacia 
SOUZA, J. R. B.; SANTOS DE JESUS, A.; FERREIRA, M. E.

Estimativa de passivos na bacia hidrográfica do Córrego Caidor, Silvânia - Goiás, como subsídio à criação de uma área de proteção ambiental

(Tabela 1). No mapa da Figura 3 é possível verificar que a classe referente à agricultura vai desde o divisor de águas até o início do terço inferior da vertente. Ao observar o mapa desta figura, é possível constatar a presença de 5 pivôs centrais de irrigação, posicionados na porção centro-sul da bacia.

No que tange à pressão sobre os cursos d'água, além da existência de pivôs de irrigação, destaca-se a existência de 7 barragens e 13 tanques (para peixes ou irrigação) nos canais fluviais (Figura 3). Como o divisor de águas está numa área de relevo plano, este favorece a instalação de indústrias e obras lineares, tais como rodovia e ferrovia, observadas no norte da bacia, onde também existe a presença de 4 indústrias/construções agrícolas localizadas adjacentes à malha viária. Essas indústrias são do ramo de tijolos e cerâmicas, e do ramo agrícola, como silos (Figura 3). Tal área plana também está associada a solos cascalhentos do tipo Plintossolo Pétrico, onde identificou-se a extração indiscriminada de cascalho laterítico (Figura 3).

As pastagens ocupam $18 \%$ da área da bacia (Tabela 1), presentes a partir do terço inferior das vertentes, limítrofes à vegetação nativa das APPs, ou por vezes as substituindo completamente, até alcançar a borda dos canais fluviais (Figura 3). A vegetação nativa, por sua vez, corresponde a 15\% da área da bacia (Tabela 1), predominando nas faixas paralelas aos cursos d'agua e compondo as APPs (Figura 3). A Silvicultura está presente em poucos pontos, em cerca de 3,3\% da área, na forma de florestas de eucalipto (Tabela 1 e Figura 3).

$\mathrm{Na}$ zona de amortecimento (ZA), a agricultura ocorre principalmente ao sul da área urbana de Silvânia, perfazendo $50 \%$ da área (Figura 4 e Tabela 2). A pastagem ocupa 23\% da área, sendo a sua maior ocorrência na porção nordeste (Tabela 2 e Figura 4). A vegetação nativa, normalmente associada às áreas de APPs e reservas legais, corresponde a 24\% da cobertura (Figura 4 e Tabela 2).

Dentro da ZA, além do uso agropecuário, há a presença de 214 barragens, 211 tanques e 24 indústrias em toda a área. Importante enfatizar que, esses dados são específicos para a ZA e não incluem os aspectos de uso e cobertura da terra cartografados dentro dos limites da bacia, explanados no parágrafo anterior. Na ZA, há também a presença de 3 áreas urbanas, sendo elas Leopoldo de Bulhões a noroeste, Silvânia na porção centro-norte e Vianópolis na porção sudeste (Figura 4). 
SOUZA, J. R. B.; SANTOS DE JESUS, A.; FERREIRA, M. E.

Estimativa de passivos na bacia hidrográfica do Córrego Caidor, Silvânia - Goiás, como subsídio à criação de uma área de proteção ambiental

Figura 3: Mapa de uso e cobertura da terra da bacia hidrográfica do córrego Caidor. A) Tanques de peixes construídos nas proximidades da captação de água; B) Pasto próximo à margem do córrego Caidor; C) Piscina construída no curso do córrego; D) Área de pastagem; E) Área de APP no córrego Caidor; F) Local da captação de água da bacia do córrego Caidor; G e H) Área de extração de cascalho laterítico

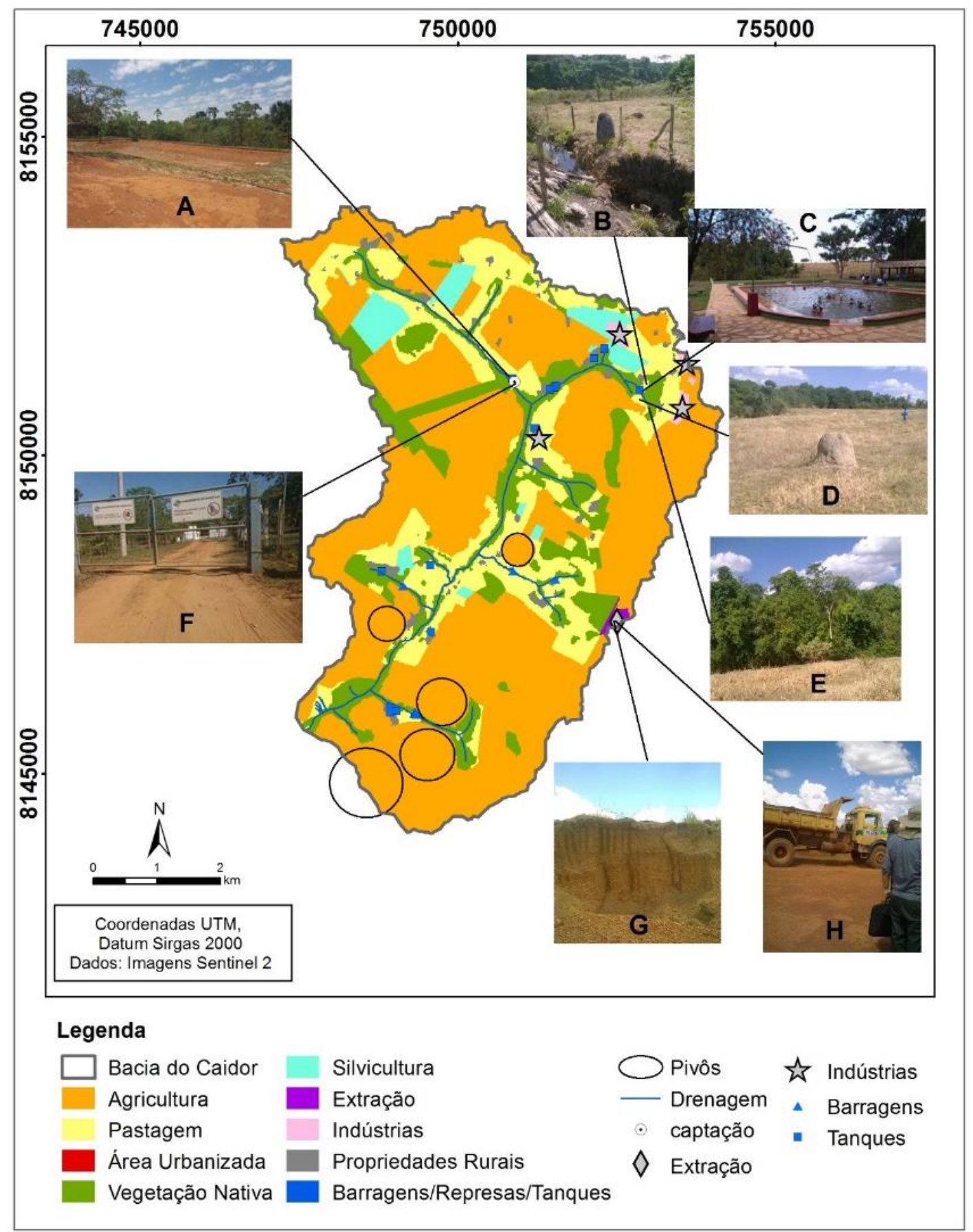

Fonte: Dados obtidos pelos autores a partir do tratamento de imagens Sentinel / 2017.

Revista Cerrados, Montes Claros/MG, v. 18, n. 02, p. 553-574, jul./dez.-2020. 
SOUZA, J. R. B.; SANTOS DE JESUS, A.; FERREIRA, M. E.

Estimativa de passivos na bacia hidrográfica do Córrego Caidor, Silvânia - Goiás, como subsídio à criação de uma área de proteção ambiental

Figura 4: Mapa de uso e cobertura da terra da zona de amortecimento (ZA) para a Área de Proteção Ambiental (APA), em processo de criação na bacia hidrográfica do córrego Caidor

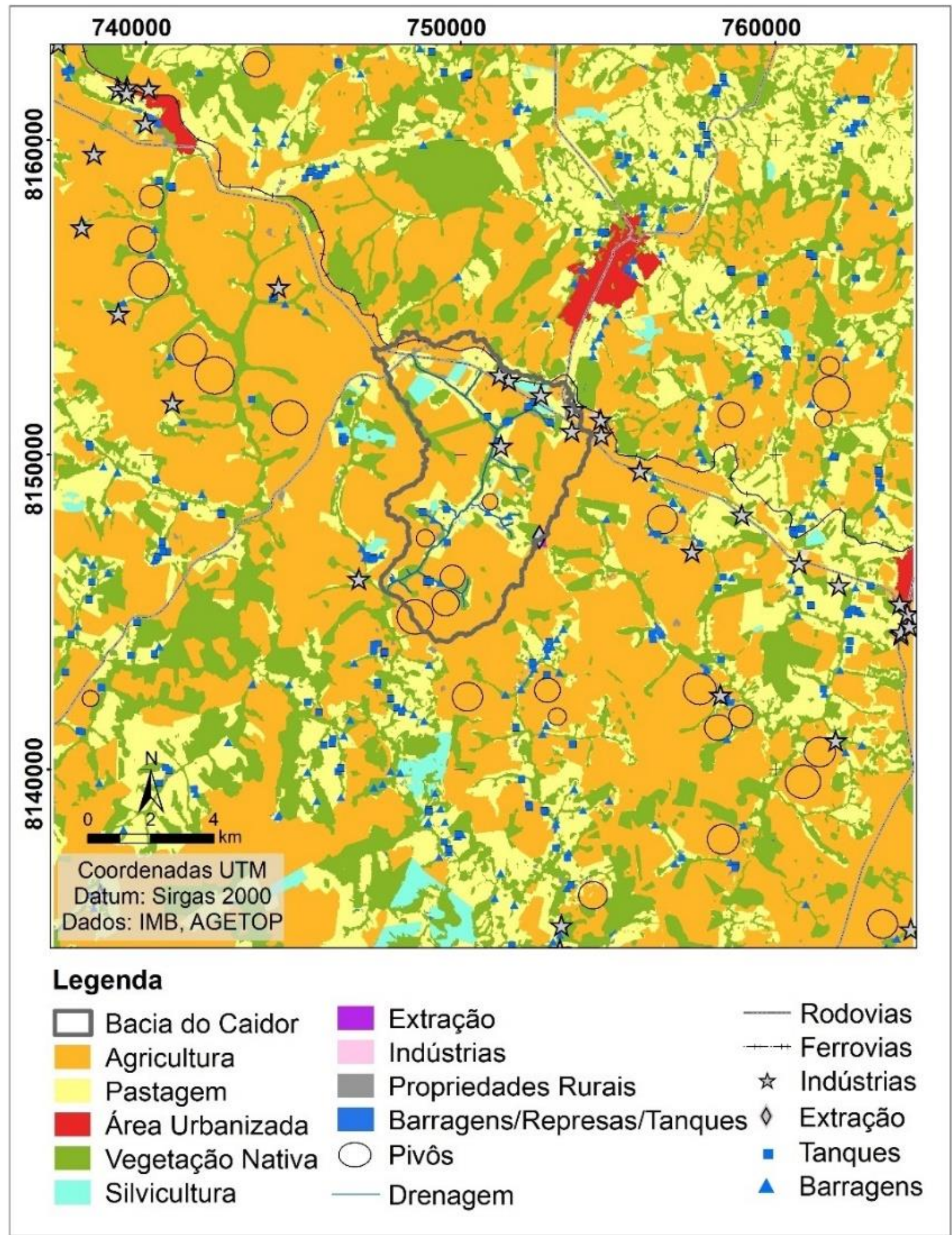

Fonte: IMB (2016), AGETOP (2012) e imagem Sentinel / 2017.

Revista Cerrados, Montes Claros/MG, v. 18, n. 02, p. 553-574, jul./dez.-2020. 
SOUZA, J. R. B.; SANTOS DE JESUS, A.; FERREIRA, M. E.

Estimativa de passivos na bacia hidrográfica do Córrego Caidor, Silvânia - Goiás, como subsídio à criação de uma área de proteção ambiental

\section{Áreas de Preservação Permanentes}

Segundo o Art. $4^{\underline{0}}$ do Código Florestal Brasileiro, considera-se Área de Preservação Permanente (APP), em zonas rurais ou urbanas, as faixas marginais de qualquer curso d'água natural, perene e intermitente, excluídos os efêmeros, desde a borda da calha do leito regular, em largura mínima de 30 metros para os cursos d'água com até 10 metros de largura. De acordo com a Lei Municipal de Silvânia 1774/14, considera-se como APP na bacia do córrego Caidor a faixa marginal localizada ao longo deste córrego, a montante da estação de captação de água da Companhia de Saneamento de Goiás S/A (Saneago), com largura de 100 metros, e de 50 metros para os afluentes deste curso.

Os mapas da Figura 5 apontam que em todos os cenários de delimitação das APPs existe algum grau de comprometimento da cobertura de dossel referente à vegetação nativa. Quando foram consideradas as tradicionais faixas de 30 metros de distância do canal fluvial, constatou-se que $\sim 14 \%$ não estavam preservadas (Tabela 3). No cenário de 50 metros, verificou-se que $\sim 22 \%$ da vegetação nativa estava suprimida (Tabela 3). Para o cenário de APPs com 100 metros, este percentual de supressão da vegetação nativa aumentou para 40\% (Tabela 3).

A distribuição espacial das áreas não preservadas não está concentrada em pontos específicos e podem ser observadas nos três cenários ao longo de todo o curso fluvial, da cabeceira ao exultório, como demonstram os mapas da Figura 5.

A Tabela 4 indica que o principal motivo para a conversão da vegetação nativa foi a implantação de pastagens. Esse cenário demonstra que a lei municipal de ampliação da faixa de APPs nessa bacia (de 30 para 100 metros) não foi suficiente para que a preservação de fato ocorresse. Diante desse cenário e no intuito de disciplinar ações quanto à manutenção, recuperação e melhoramento dos serviços ambientais, bem como estimular a conservação ambiental no âmbito municipal, a prefeitura de Silvânia, tendo como base (entre outras análises) o presente estudo, aprovou e sancionou a Lei $\mathrm{n}^{\circ} 1.938 / 18$, de 21 de dezembro de 2018, referente à Política Municipal de Serviços Ambientais (PMSA) e Programa de Pagamento por Serviços Ambientais (PSA). 
SOUZA, J. R. B.; SANTOS DE JESUS, A.; FERREIRA, M. E.

Estimativa de passivos na bacia hidrográfica do Córrego Caidor, Silvânia - Goiás, como subsídio à criação de uma área de proteção ambiental

Figura 5: Mapeamento da cobertura de dossel em três cenários de APPs: a) 30 m; b) 50 m; c) $100 \mathrm{~m}$

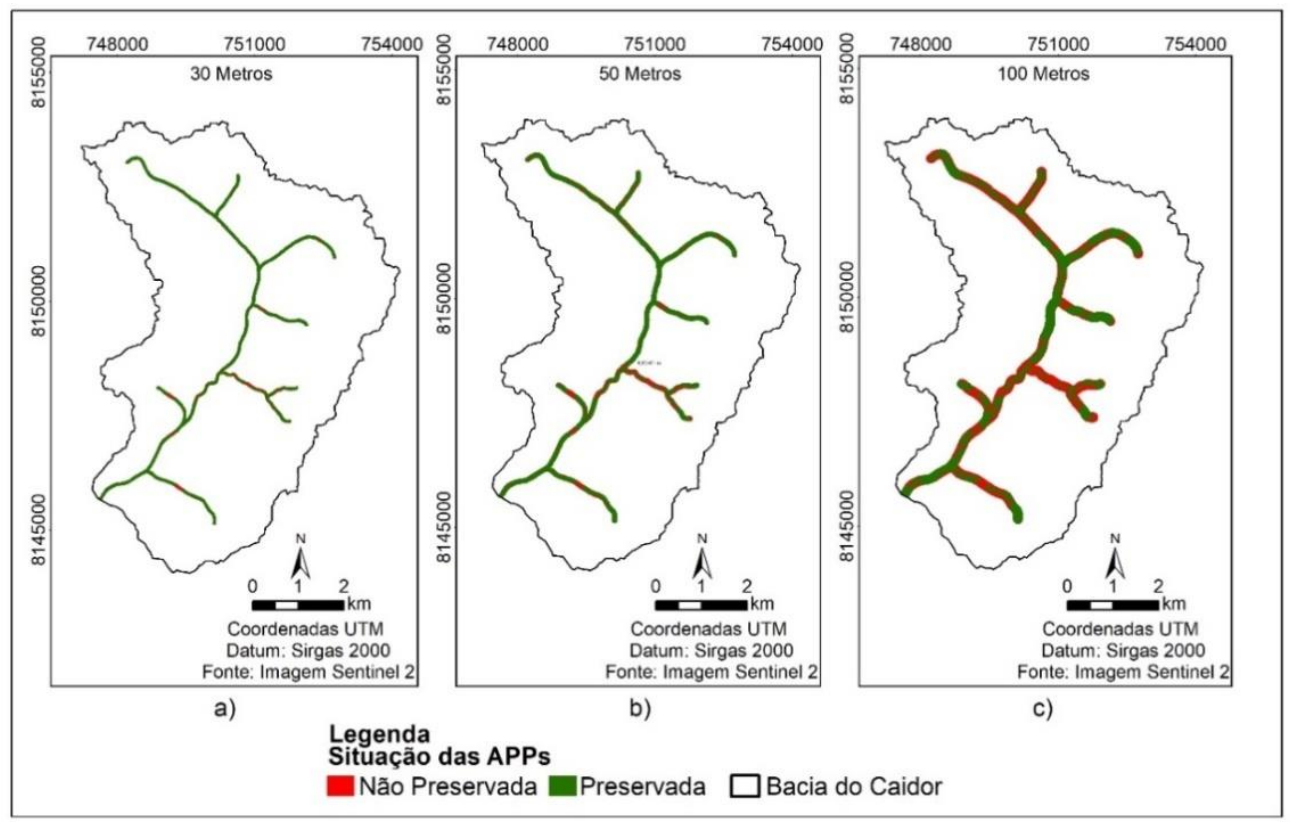

Fonte: IMB (2016), AGETOP (2012) e imagem Sentinel / 2017.

Tabela 3 - Dados de Preservação das APPs

\begin{tabular}{|c|c|c|c|c|c|c|c|c|c|}
\hline \multirow[t]{2}{*}{ Situação APPs } & \multicolumn{3}{|c|}{$30 \mathrm{~m}$} & \multicolumn{3}{|c|}{$50 \mathrm{~m}$} & \multicolumn{3}{|c|}{$100 \mathrm{~m}$} \\
\hline & $\begin{array}{l}\text { Área } \\
\mathrm{km}^{2}\end{array}$ & $\begin{array}{c}\text { Área } \\
\text { ha }\end{array}$ & $\%$ & $\begin{array}{l}\text { Área } \\
\mathrm{km}^{2}\end{array}$ & $\begin{array}{c}\text { Área } \\
\text { ha }\end{array}$ & $\%$ & $\begin{array}{l}\text { Área } \\
\mathrm{km}^{2}\end{array}$ & $\begin{array}{c}\text { Área } \\
\text { ha }\end{array}$ & $\%$ \\
\hline Preservado & 1,3 & 127,6 & 85,7 & 1,9 & 192 & 78,1 & 2,8 & 286,3 & 59,2 \\
\hline Não Preservado & 0,2 & 21,3 & 14,3 & 0,5 & 53,8 & 21,9 & 2 & 196,9 & 40,8 \\
\hline Total & 1,5 & 148,9 & 100 & 2,4 & 245,8 & 100 & 4,8 & 483,2 & 100 \\
\hline
\end{tabular}

Fonte: Dados obtidos pelos autores a partir do tratamento de imagens Sentinel / 2017.

Tabela 4 - Dados de ocupação das APPs

\begin{tabular}{|c|c|c|c|c|c|c|c|c|c|}
\hline \multirow{2}{*}{$\begin{array}{c}\text { Uso e cobertura da } \\
\text { terra }\end{array}$} & \multicolumn{3}{|c|}{$30 \mathrm{~m}$} & \multicolumn{3}{|c|}{$50 \mathrm{~m}$} & \multicolumn{3}{|c|}{$100 \mathrm{~m}$} \\
\hline & $\begin{array}{l}\text { Área } \\
\mathrm{Km}^{2}\end{array}$ & $\begin{array}{l}\text { Área } \\
\text { Ha }\end{array}$ & $\%$ & $\begin{array}{l}\text { Área } \\
\mathrm{Km}^{2}\end{array}$ & $\begin{array}{l}\text { Área } \\
\mathrm{Ha}\end{array}$ & $\%$ & $\begin{array}{l}\text { Área } \\
\mathrm{Km}^{2}\end{array}$ & $\begin{array}{l}\text { Área } \\
\mathrm{Ha}\end{array}$ & $\%$ \\
\hline Agricultura & 0,01 & 0,8 & 0,005 & 0,04 & 4,6 & 1,9 & 0,35 & 35,5 & 7,3 \\
\hline $\begin{array}{l}\text { Barragens/Represas/ } \\
\text { Tanques }\end{array}$ & 0,02 & 2,4 & 1,6 & 0,03 & 3,05 & 1,2 & 0,03 & 3,7 & 1,3 \\
\hline Pastagem & 0,15 & 15,6 & 10,5 & 0,4 & 40,1 & 16,3 & 1,3 & 134,6 & 27,8 \\
\hline P. Rurais & 0,02 & 2,3 & 1,6 & 0,05 & 5,9 & 2,4 & 0,2 & 21 & 4,3 \\
\hline V. Nativa & 1,27 & 127,6 & 85,7 & 1,92 & 192 & 78,1 & 2,8 & 286,3 & 59,2 \\
\hline Silvicultura & - & - & - & 0,0003 & 0,03 & 0,01 & 0,01 & 1,9 & 0,4 \\
\hline Total & 1,48 & 148,9 & 100 & 2,45 & 245,8 & 100 & 4,8 & 483,2 & 100 \\
\hline
\end{tabular}

Fonte: Dados obtidos pelos autores a partir do tratamento de imagens Sentinel / 2017.

Tal conduta da gestão municipal segue os princípios do "programa produtor de água”. O Programa usa o conceito do Pagamento por Serviços Ambientais (PSA), que 
SOUZA, J. R. B.; SANTOS DE JESUS, A.; FERREIRA, M. E.

Estimativa de passivos na bacia hidrográfica do Córrego Caidor, Silvânia - Goiás, como subsídio à criação de uma área de proteção ambiental

estimula os produtores a investirem na proteção do meio ambiente, recebendo apoio técnico e financeiro para implementação de práticas conservacionistas (via Agência Nacional de Águas - ANA).

\section{Avaliação de Passivos Ambientais em Relação às Propriedades}

Segundo o novo Código Florestal, as pequenas propriedades (entre 1 e 4 módulos fiscais) e minifúndios (menor que 1 módulo fiscal) não são obrigados a ter reserva legal (BRASIL, 2012). Nessa pesquisa, a menção aos passivos ambientais em pequenas propriedades e minifúndios refere-se apenas à falta de APPs ao longo dos cursos hidrográficos. Esta análise de passivos ambientais foi gerada com dados do CAR e IMAFLORA (Figura 6), onde a ausência de passivos está destacada na cor verde, enquanto a sua presença está destacada na cor vermelha.

Figura 6: Mapa de passivo ambiental na bacia do Caidor, segundo os dados de propriedades. a) CAR; b) IMAFLORA

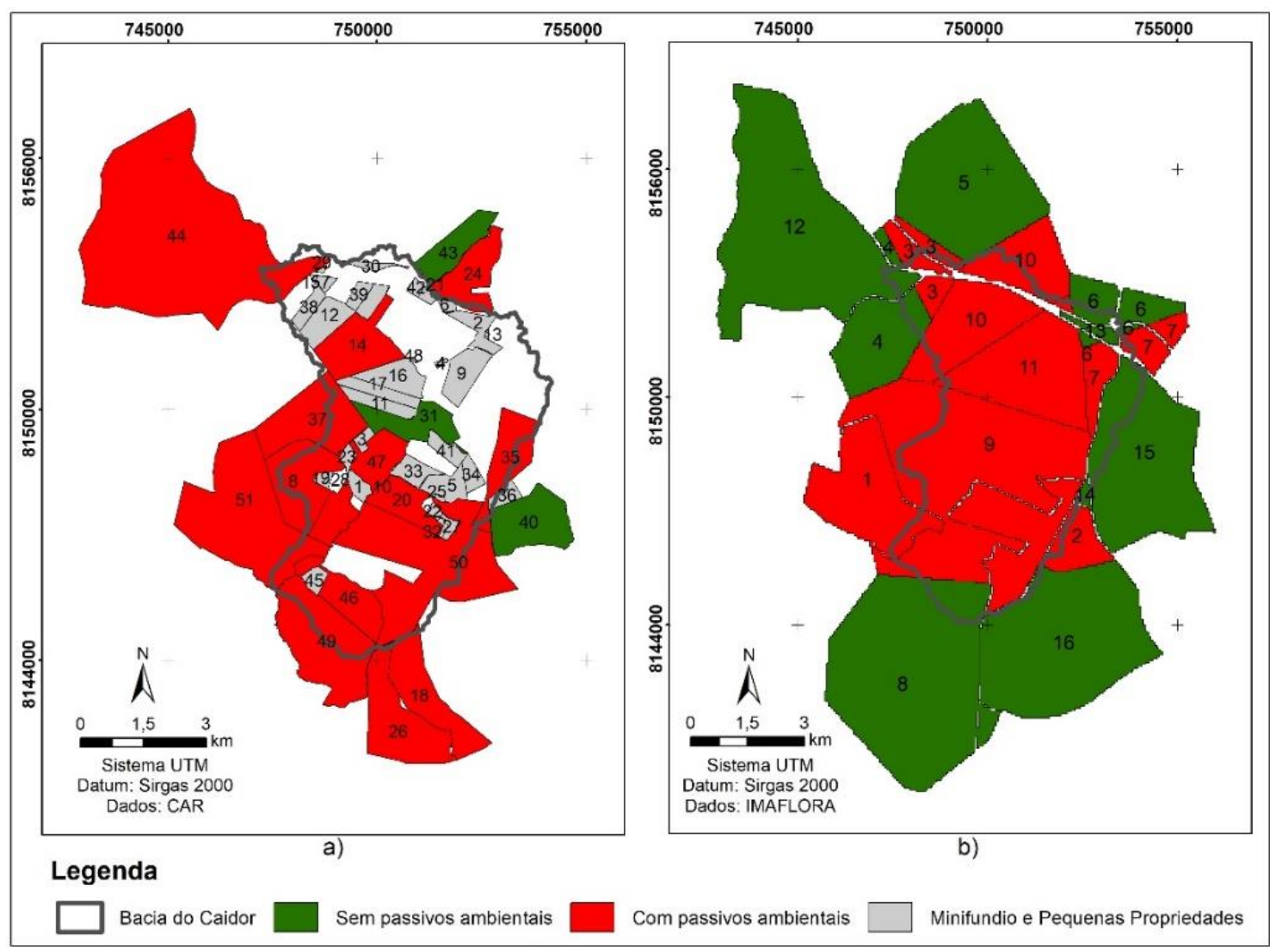

Fonte: CAR (2017), IMAFLORA (2017).

Revista Cerrados, Montes Claros/MG, v. 18, n. 02, p. 553-574, jul./dez.-2020. 
SOUZA, J. R. B.; SANTOS DE JESUS, A.; FERREIRA, M. E.

Estimativa de passivos na bacia hidrográfica do Córrego Caidor, Silvânia - Goiás, como subsídio à criação de uma área de proteção ambiental

O mapa da Figura 6a indica que, das 51 propriedades da base de dados do CAR, 14 possuem de 1 a 5 critérios para passivos ambientais. Das propriedades com passivo ambiental, 10 contam com reserva legal inferior a 20\%; 10 possuem tanques e barragens no canal fluvial; 4 possuem indústrias/construções agrícolas; 1 possui extração de cascalho. Por fim, destaca-se que 25 propriedades estão com a preservação das APPs comprometidas, ou seja, quase $50 \%$ das propriedades possuem passivos ambientais associados à supressão da vegetação nativa em área de APP.

O mapa da Figura $6 \mathrm{~b}$ indica, segundo dados do IMAFLORA, que 8 das 16 propriedades cartografadas possuem de 1 a 3 critérios para passivos ambientais. A Tabela 6 demonstra que 4 propriedades estão com reserva legal inferior a 20\%; 2 propriedades possuem tanques e barragens no canal fluvial; 4 contam com indústrias e construções agrícolas, sendo sete propriedades com problemas de preservação das APPs, ou seja, pouco mais de $50 \%$ das propriedades dessa base de dados estão associadas à supressão da vegetação nativa em área de APP. Das quatro classes de passivos ambientais listadas na Tabela 5 e 6 , algumas propriedades acumulam até 3 delas.

Tabela 5: Diagnósticos de Passivos Ambientais segundo dados do CAR

\begin{tabular}{lllll}
\hline $\begin{array}{l}\text { Reserva Legal } \\
\text { inferior a 20\% }\end{array}$ & $\begin{array}{l}\text { Tanques/ } \\
\text { Barragens }\end{array}$ & $\begin{array}{l}\text { Indústria/ } \\
\text { Construções } \\
\text { agrícolas }\end{array}$ & $\begin{array}{l}\text { *APP não preservada } \\
\text { em sua totalidade }\end{array}$ & $\begin{array}{l}\text { Área de empréstimo/ } \\
\text { Extração de laterita. }\end{array}$ \\
\hline $\begin{array}{l}\text { Propriedade } 8,14, \\
18,26,37,44,46,\end{array}$ & $\begin{array}{l}\text { Propriedade } \\
18,20,24,26,\end{array}$ & $\begin{array}{l}\text { Propriedade } \\
\text { 4, } 11,13 \text { e } 15\end{array}$ & $\begin{array}{l}\text { Propriedade } 1,2,4,5, \\
6,9,10,12,14,15,16,\end{array}$ & Propriedade 35 \\
47,50 e 51 & $44,46,47,4$, & & $19,20,22,25,31,33$, & \\
& 50 e 51 & & $39,4446,47,48,49$, & \\
& & 50,51 & \\
\hline
\end{tabular}

*APP de 50 metros, segundo lei específica do município para a bacia em questão.

Fonte: Dados obtidos pelos autores a partir do tratamento de imagens Sentinel / 2017.

Tabela 6: Diagnósticos de Passivos Ambientais segundo dados do IMAFLORA

\begin{tabular}{llll}
\hline $\begin{array}{l}\text { Reserva Legal } \\
\text { inferior a 20\% }\end{array}$ & Tanques/Barragens & $\begin{array}{l}\text { Indústria/construções } \\
\text { agrícolas }\end{array}$ & $\begin{array}{l}\text { *APP não preservada em } \\
\text { sua totalidade }\end{array}$ \\
\hline $\begin{array}{l}\text { Propriedade 1, } \\
2,7,9\end{array}$ & Propriedade 2 e 11 & Propriedade $7,11,13$ e 15 & $\begin{array}{l}\text { Propriedade } 1,2,6,7,9,10 \\
\text { e } 11\end{array}$ \\
& & &
\end{tabular}

*APP de 50 metros, segundo lei específica do município para a bacia em questão.

Fonte: Dados obtidos pelos autores a partir do tratamento de imagens Sentinel / 2017. 
SOUZA, J. R. B.; SANTOS DE JESUS, A.; FERREIRA, M. E.

Estimativa de passivos na bacia hidrográfica do Córrego Caidor, Silvânia - Goiás, como subsídio à criação de uma área de proteção ambiental

\section{CONSIDERAÇÕES FINAIS}

A criação de uma APA pode se somar à lei de Pagamento por Serviços Ambientais, contribuindo para a conservação da bacia do córrego Caidor, sobretudo de seu manancial de água (incluindo as nascentes), ao minimizar o processo erosivo do solo e, consequentemente, auxiliar na manutenção da qualidade da água e biodiversidade locais.

Os dados apresentados nesta pesquisa demonstram a importância de criação de uma APA na área de estudo, podendo influir na modificação e/ou adaptações do tipo de ocupação na referida bacia hidrográfica, bem como adoção de técnicas de manejo mais eficientes para a produção agropecuária, com menor impacto ao meio ambiente.

Os dados de propriedades do CAR e do IMAFLORA são interessantes do ponto de vista do código florestal, servindo de base para se questionar a inexistência de Reserva Legal e APP em propriedades de pequeno e médio porte. No entanto, os dados do CAR ainda estão defasados quanto à totalidade de propriedades cadastradas, atingindo $25 \%$ da bacia. Espera-se que tal lacuna no cadastro seja em breve resolvida pelo poder público estadual e federal.

As metodologias utilizadas no estudo podem ser consideradas eficientes, levando-se em consideração os seus objetivos, ao identificar as áreas de uso e ocupação irregulares, relacioná-las quanto à legislação ambiental vigente e elencar as propriedades com passivos ambientais. A bacia apresenta uso da terra consolidado na agricultura e pecuária, presentes em aproximadamente $80 \%$ da área de estudo. Os problemas advindos dessas atividades são: os avanços sobre as áreas de APPs; maior demanda de água pela agricultura e suas barragens para irrigação por pivôs; pisoteio de gado em áreas de APPs, especialmente em nascentes.

Já em relação à área de extração de cascalho laterítico inserida na bacia do Caidor, recomenda-se atenção especial, pois a área está aberta e abandonada, podendo resultar no surgimento de um depósito de lixo irregular, à céu aberto (conhecido no Brasil como "lixão"), sujeita também à erosão e contaminação do solo e reservatórios d'água subterrâneos. Por outro lado, esta área não se mostra interessante para a instalação de um aterro sanitário, principalmente por se encontrar em um divisor de águas de uma bacia com captação de água para abastecimento público. Por isso, a recomendação é de cercamento da cava de extração e 
SOUZA, J. R. B.; SANTOS DE JESUS, A.; FERREIRA, M. E.

Estimativa de passivos na bacia hidrográfica do Córrego Caidor, Silvânia - Goiás, como subsídio à criação de uma área de proteção ambiental

implantação de um plano de recuperação da área degradada, incluindo a restauração florestal.

O modelo de estudo proposto nesta comunicação científica pode ser útil em diversas outras bacias do bioma Cerrado, no que tange na identificação de passivos ambientais e propositura de ampliação das faixas de APPs, bem como na aplicação de leis referentes ao pagamento por serviços ambientais.

Como alternativa de manejo para a bacia do Caidor, sugere-se a técnica de integração lavoura-pecuária-floresta (ILPF). Essa é uma estratégia de produção que integra diferentes sistemas produtivos, agrícolas, pecuários e florestais dentro de uma mesma área, tida atualmente como uma estratégia de produção sustentável. O sistema ILPF tem se consolidado no Brasil como importante opção para o setor produtivo agropecuário (por exemplo, via Empresa Brasileira de Pesquisa Agropecuária - EMBRAPA).

\section{AGRADECIMENTOS}

À prefeitura de Silvânia, em especial à equipe da Secretaria de Meio Ambiente e da Defesa Civil, aqui representados pelos servidores públicos Francisco José Tavares e Líbia Marques, ao garantir apoio logístico e suporte para atividades de campo na bacia do Caidor. Ao Conselho Nacional de Desenvolvimento Científico (CNPq), pelo apoio ao projeto PELDCOFA, sob coordenação da professora Dra. Rosane Garcia Collevatti (Dep. Ecologia / UFG). Agradecimentos também ao Critical Ecosystem Partnership Fund (CEPF - Cerrado), pelo apoio ao Lapig / UFG no desenvolvimento da Plataforma de Conhecimento do Cerrado (projeto \#CEPF-103768).

\section{REFERÊNCIAS}

AGÊNCIA NACIONAL DE ÁGUAS. Programa Produtor de água. Plataforma digital. Disponível em: <http://www3.ana.gov.br/portal/ANA/programas-projetos/programaprodutor-de-agua >. Acesso em: 27 de maio de 2018.

BRASIL. Lei n. ${ }^{\circ}$ 9.985, de 18 de julho de 2000. Sistema Nacional de Unidades de Conservação da Natureza. Disponível em: <http://www.planalto.gov.br/ccivil_03/leis/ 19985.htm>. Acesso em: 08 abril 2018.

BRASIL. Lei n. ${ }^{\circ} 12.651$, de 25 de maio de 2012. Código Florestal Brasileiro. Disponível em: <http://www.planalto.gov.br/ccivil_03/_ato2011-2014/2012/lei/112651.htm>. Acesso em: 02 de junho de 2020.

CONSELHO NACIONAL DE MEIO AMBIENTE. Resolução nº 010 de 14 de dezembro de 1988. Dispõe sobre a regulamentação das Áreas de Proteção Ambiental. Disponível em: 
SOUZA, J. R. B.; SANTOS DE JESUS, A.; FERREIRA, M. E.

Estimativa de passivos na bacia hidrográfica do Córrego Caidor, Silvânia - Goiás, como subsídio à criação de uma área de proteção ambiental

<http://www.mma.gov.br/port/conama/res/res88/res1088.ht ml >. Acesso em: 24 de maio de 2018

EMPRESA BRASILEIRA DE PESQUISA AGROPECUÁRIA. Módulos Fiscais. Disponível em: 〈https://www.embrapa.br/codigo-florestal/area- de-reserva-legal-arl/modulo-fiscal〉.

Acesso em: novembro de 2017.

EMPRESA BRASILEIRA DE PESQUISA AGROPECUÁRIA. O que é ILPF? Disponível em: < https://www.embrapa.br/web/rede-ilpf/o-que-e>. Acesso em: 27 de maio de 2018. INSTITUTO BRASILEIRO DE GEOGRAFIA E ESTATÍSTICA. Censo Agropecuário 2017 - Resultados definitivos. IBGE. Plataforma digital. Disponível em: <https://censos.ibge.gov.br/ agro/2017/>. Acesso em: 02 de junho de 2020.

INSTITUTO BRASILEIRO DO MEIO AMBIENTE E DOS RECURSOS NATURAIS RENOVÁVEIS. Guia de Procedimentos do Licenciamento Ambiental Federal. Documento de Referência. Brasília: IBAMA, 2002. Cap. 3. Disponível em: <https://www.mma.gov.br/estruturas/sqa_pnla/arquivos/Procedime ntos.pdf $>$.

INSTITUTO BRASILEIRO DE GEOGRAFIA E ESTATÍSTICA. IBGE Cidades. 2020. Disponível em: < https://cidades.ibge.gov.br/brasil/go/silvania/panorama > Acesso em: $10 \mathrm{de}$ Maio de 2020.

INSTITUTO BRASILEIRO DE GEOGRAFIA E ESTATÍSTICA. Manual técnico de uso da terra. Coordenação de Recursos Naturais e Estudos Ambientais. - 3. ed. - Rio de Janeiro, 2013. $171 \mathrm{p}$.

PECCINI, A. Contabilidade ambiental - conceito, aplicabilidade e campo de atuação. Rio de Janeiro, 2012.

SILVÂNIA. Lei n ${ }^{\circ} 1774$, de 1 de setembro de 2014. Código de Meio Ambiente do Município de Silvânia/GO. Disponível em: 〈http://www.camaradesilvania.go.gov.br/ legislacao/leis/2014/lei1774.pdf>. Acesso em: 27 de maio de 2018.

\section{Autores}

Jaila Raiane Barbosa de Souza - É Graduada em Ciências Ambientais pela Universidade Federal de Goiás (UFG). Atualmente é Mestranda pelo Programa de Pós-graduação em Geografia da Universidade Federal de Goiás (UFG).

Andrelisa Santos de Jesus - É Graduada e Mestre em Geografia pela Universidade Federal de Goiás (UFG) e Doutora em Geotecnia pela Universidade de Brasília (UnB). Atualmente é Professora do Instituto de Estudos Socioambientais da Universidade Federal de Goiás (IESA/UFG). 
SOUZA, J. R. B.; SANTOS DE JESUS, A.; FERREIRA, M. E.

Estimativa de passivos na bacia hidrográfica do Córrego Caidor, Silvânia - Goiás, como subsídio à criação de uma área de proteção ambiental

Manuel Eduardo Ferreira - É Graduado em Geografia pela Universidade de Brasília (UnB), Mestre em Geologia pela Universidade de Brasília (UnB) e Doutor em Ciências Ambientais pela Universidade Federal de Goiás (UFG). Atualmente é Professor do Instituto de Estudos Socioambientais da Universidade Federal de Goiás (IESA/UFG) e de seu Programa de Pós-Graduação em Geografia (PPGeo).

Artigo recebido em: 03 de junho de 2020.

Artigo aceito em: 24 de novembro de 2020.

Artigo publicado em: 22 de dezembro de 2020. 